\title{
Effects of Polymeric Dielectric Morphology on Pentacene Morphology and Organic TFT Characteristics
}

\author{
Rongbin $\mathrm{YE}^{*}$, Koji Ohta and Mamoru Baba \\ Faculty of Engineering, Iwate University, Ueda 4-3-5, Morioka 020-8551, Japan
}

\begin{abstract}
In this paper, we report on the effects of the polymeric dielectric morphology on pentacene morphology and organic thin film transistor (TFT) characteristics. The morphology and thickness of cyclo-olefin polymer (COP) dielectric could be controlled by selecting a solvent. Higher the solvent's boiling point is, thinner and smother COP films could be obtained. Using the solvent of trimethylcyclohexane, the spin-coated COP films of ca. $330 \mathrm{~nm}$ with the peak-to-valley of $7.35 \mathrm{~nm}$ and the roughness of root mean square of $0.58 \mathrm{~nm}$ were obtained, and pentacene TFT showed high mobility of $2.0 \mathrm{~cm}^{2} \mathrm{~V}^{-1} \mathrm{~s}^{-1}$, which originated from highly ordering of pentacene thin films deposited on the smoother and thinner COP films.
\end{abstract}

\section{Introduction}

Organic thin film transistors (OTFTs) offer a promising technology for low-cost and large-area electronic applications such as active-matrix displays, electronic papers, flexible microelectronics and chemical sensor arrays [1]. Generally, the deposition of inorganic dielectrics would be difficult on top of organic semiconductors. The surface treatments employed on inorganics would be practically impossible to use in top gate devices. Organic dielectrics offer the freedom to build both top and bottom gate devices more easily by the use of solution coating techniques and printing. Thus polymeric dielectrics have been considered as preferable gate dielectric materials due to their numerous advantages over inorganic materials: i.e., flexible, hydrophilic, easy process, and low cost. In the previous study, we have been studied low-k cyclo-olefin polymer (COP, ZEONEX 480R) as a gate dielectric [2]. Due to the hydroxyl-free and low water absorbent insulator, the pentacene TFTs showed negligible current hysteresis. On the other hand, it has been known that the surface energy of gate dielectrics strongly influences organic film morphology and device characteristics [3]. In this study, we report on the effects of the gate-dielectric morphology on pentacene morphology and OTFT characteristics. The morphology of the polymer dielectric could be controlled by various boiling point (BP) solvents.

* Corresponding author: ye@iwate-u.ac.jp 


\section{Experimental}

OTFTs were fabricated using the top contact structure shown in Fig. 1(a). Al thin films of $100 \mathrm{~nm}$ were deposited on $100 \mu \mathrm{m}$ flexible substrates (ZF14-100, ZEON) to be used as the gate electrodes. ZEONEX 480R (5 wt. \%, ZEON) were spun on Al electrodes at $2000 \mathrm{rpm}$ for $30 \mathrm{~s}$ using solvents of cyclohexane (BP: $81{ }^{\circ} \mathrm{C}$, COP1 films named) and trimethylcyclohexane (BP: $136.6{ }^{\circ} \mathrm{C}, \mathrm{COP} 2$ films named). To ensure that the solvents were removed from the COP films, these dielectric films were annealed at $60{ }^{\circ} \mathrm{C}$ in air atmosphere for $1 \mathrm{~h}$. Pentacene purified by sublimation was purchased commercially (Tokyo Kasei). Pentacene thin films of ca. $50 \mathrm{~nm}$ were deposited at room temperature under a base pressure of less than $4.0 \times 10^{-4} \mathrm{~Pa}$. Film thickness and growth rates were monitored by a thickness and rate monitor (CRTM-6000, ULVAC). The source and drain electrodes of $20 \mathrm{~nm} \mathrm{Au}$ films were deposited through a shadow mask. The channel width is $1 \mathrm{~mm}$ and the channel length is $80 \sim 100 \mu \mathrm{m}$. The characteristics of OTFTs were measured with a two-channel voltage current source/monitor system (Advantest R6245) under ambient laboratory air conditions. Furthermore, we also fabricated MIM (Metal-Insulator-Metal) capacitors shown in Fig. 1(c) to analyze the electrical properties of COP thin films, and a device area was $1 \mathrm{~mm} \times 1 \mathrm{~mm}$. C-f characteristics were measured using a LCR meter (4284A, HP).

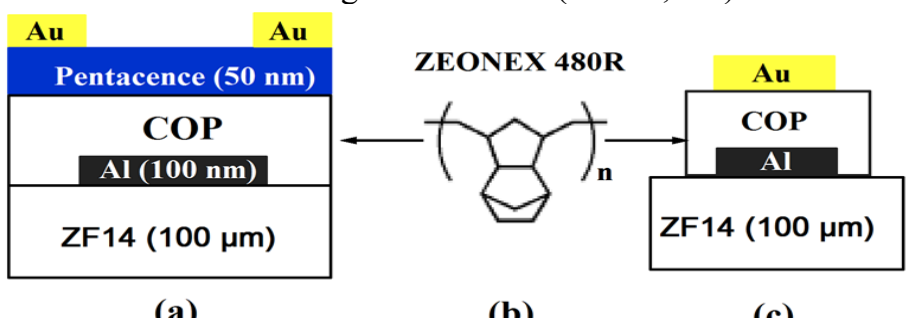

(a)

(b)

(c)

Fig.1(a)Schematic structures of(a) OTFT,(b)chemical structure of ZEONEX $480 \mathrm{R}$ and (c) $\mathrm{MIM}(\mathrm{AI} / \mathrm{COP} / \mathrm{Au})$ capacitor

The XRD analysis was performed on a diffractometer (Rint 2200V, RIGAKU) with graphite monochromatized CuK $\alpha$ radiation $(\lambda=1.54 \AA$ ). The morphology of these films was examined using AFM (Nanocute, SII); the cantilevers were used in the tapping mode with a length of $90 \mu \mathrm{m}$ and a force constant of $0.12 \mathrm{~N} / \mathrm{m}$. The peak-to-valley (P-V), the roughness of root mean square (RMS) and grain size (GS) were given by the AFM instrument for the individual scans $(10 \mu \mathrm{m} \times 10 \mu \mathrm{m})$.

\section{Results and Discussions}

Figures 2 shows AFM topographic images of COP films spun on Al electrodes. As shown in Fig. 2a, a swirling pattern may be observed. On the contrary, a smooth film is obtained in Fig. 2b. It has been known that many parameters such as the solvent quality, solution viscosity and solvent vapor post-treatment control the resulting structure on spin-coated polymer films [4-8]. Lower the solvent's BP is, faster the volatile organic solvent evaporates during the spin-coating process. The wonder difference of the two COP films is due to the two solvents' PB. By detailed AFM analysis, the values of P-V and RMS are $198 \mathrm{~nm}$ and 29 $\mathrm{nm}$ for the COP1 film, and $7.35 \mathrm{~nm}$ and $0.58 \mathrm{~nm}$ for the COP2 film, respectively. 


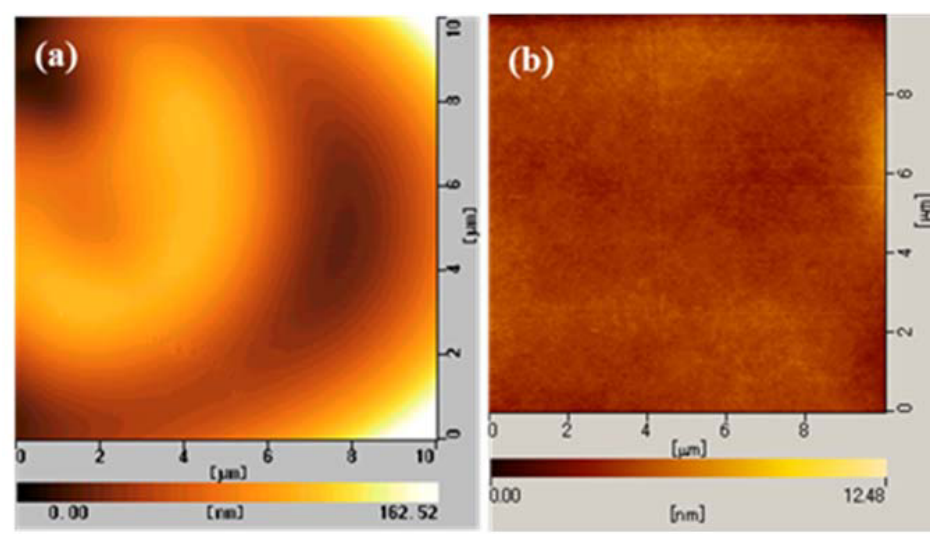

Fig .2 AFM topographic images of COP films spun on AL electrodes:(a)COP1 film and (b)COP2 film

Figure 3 a shows the frequency dependence of the capacitance $\left(\mathrm{C}_{\mathrm{i}}\right)$ of the COP films. At 1 $\mathrm{KHz}, \mathrm{C}_{\mathrm{i}}$ of the COP films were 4.55 and $6.54 \mathrm{nF} / \mathrm{cm}^{2}$, and were not changed very much in range of frequencies from $20 \mathrm{~Hz}$ to $1 \mathrm{MHz}$, which indicates that there are few impurities in the dielectric films. The dielectric constant $(\varepsilon)$ of COP films is 2.3 , thus the film thicknesses of the COP films were about $450 \mathrm{~nm}$ and $330 \mathrm{~nm}$. Generally, the thickness of the resulting films depends on the concentration of the polymer in solution, polymer molecular weight, spinning velocity and spinning time [9-11]. Thus, the thinner COP films could be obtained with the higher BP solvent. Figure $3 \mathrm{~b}$ shows the leakage currents $(\mathrm{J})$ through the dielectric layers as a function of electric field applied across the capacitor. Any breakdown was not observed under $1.82 \mathrm{MV} / \mathrm{cm}$ and the conductivity of COP films was smaller than $5.5 \times 10^{-14}$ $\mathrm{S} / \mathrm{cm}$. These excellent insulating properties are due to no polar dipoles and few impurities in the dielectric films [12].

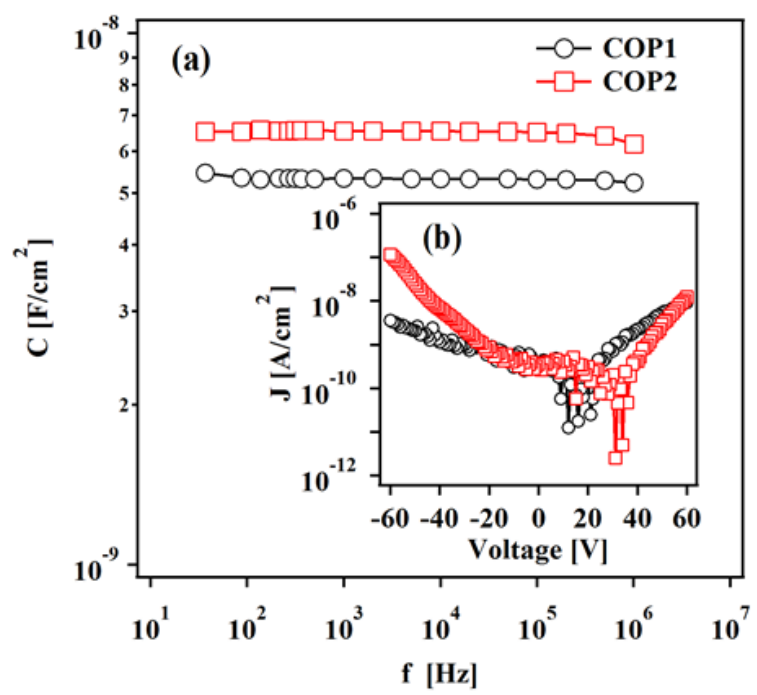

Fig 3.(a) frequency dependence of Ci of an MIM and (b) leakage current characteristic of the MIM structure as a function of the applied voltage 


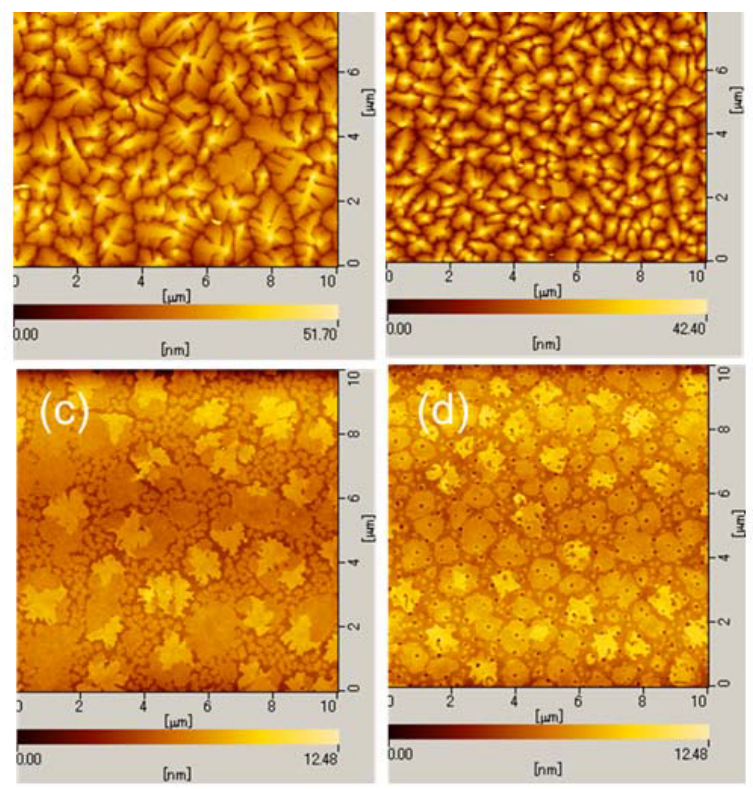

Fig.4 AFM topographic images of pentacene thin films fo ca.50 nm deposited on (a) COPI film and (b) COP2 film, and ca.2 nm on(c) COP1 film and (d) COP2 film,respectively

Figure $4 \mathrm{a}$ and $4 \mathrm{~b}$ show AFM topographic images of pentacene thin films of ca. $50 \mathrm{~nm}$ deposited on the COP films. Dendritic grains were observed and these grain structures grow using the Stranski-Krastanov growth mode (two-dimensional growth), as shown in Fig. 4c and $4 \mathrm{~d}$. Due to low energy and smoother surface, pentacene molecules more easily diffuse on the COP2 films than on the COP1 films. Thus the pentacene morphology on the COP2 sample had smaller grains and more dense than that on the COP1 sample. By AFM qualitative analysis, the values of GS and RMS are $800 \mathrm{~nm}$ and $7.4 \mathrm{~nm}$ for the COP1 sample (Fig. 4a), and $706 \mathrm{~nm}$ and $6.8 \mathrm{~nm}$ for the COP2 sample (Fig. 4b), respectively.

Figure 5 shows XRD patterns of the pentacene thin films (shown in Fig. 4a and 4b). The presence of only a (001) reflection and the absence of any other (hkl) reflections indicate that all the crystals in the films are oriented with their $(001)$ planes $\left(\mathrm{d}_{001}=1.54 \mathrm{~nm}\right)$ parallel to the substrates. By qualitative XRD analysis, the full width at half maximum of the 001 diffraction line of the COP2 sample is smaller than that of the COP1 sample, and moreover the fourth-order diffraction peak was observed in the COP2 sample. These results imply that highly ordering pentacene thin films could be deposited on the COP2 film. 


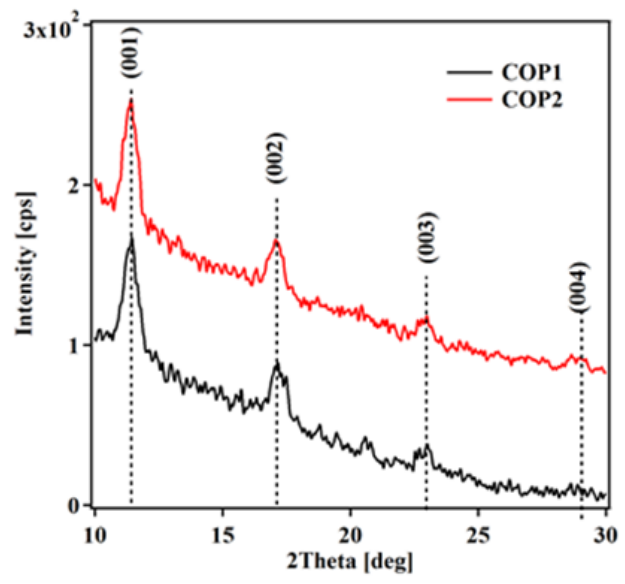

Fig. 5 XRD pattems of the pentacene thin films of ca. $50 \mathrm{~nm}$ deposited on (a) COP1 film and (b) COP2 film(shown in Fig.4a and 4b)
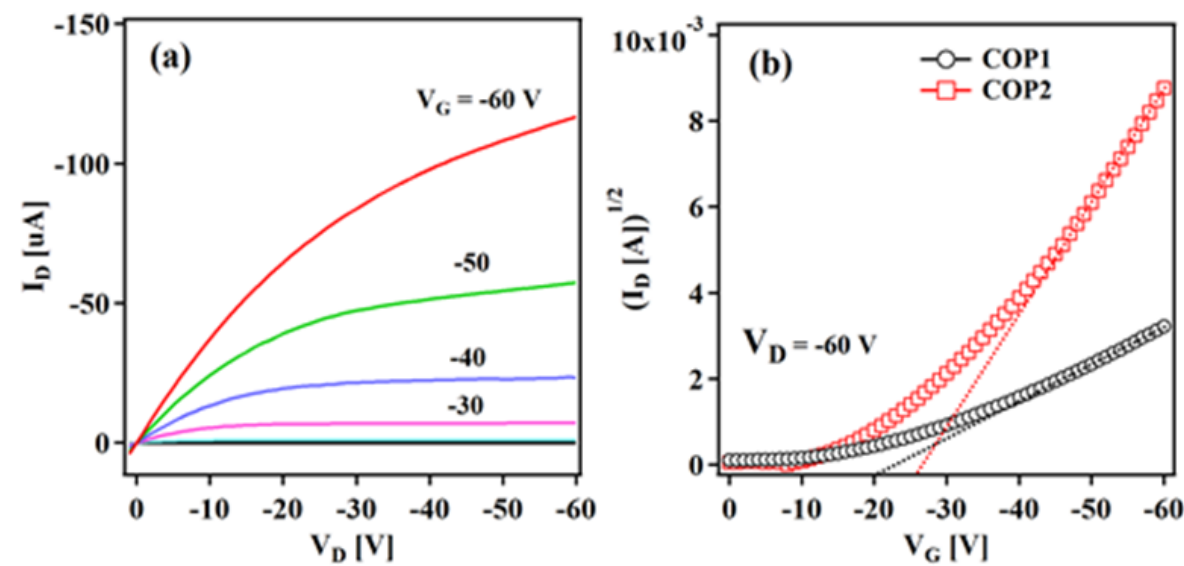

Fig.6(a) Output characteristic of a flexible pentacene TFT prepared with the COP2 dielectric and (b) transfer characteristic of the COP1 device and the COP2 device

Figure 6a shows the output characteristics of a pentacene TFT with the COP2 film as gate dielectrics. The linear and saturation regions can be observed with the increase of drain voltage $\left(\mathrm{V}_{\mathrm{D}}\right)$ and gate voltage $\left(\mathrm{V}_{\mathrm{G}}\right)$. The device typically worked in a p-channel accumulation mode. Generally, the device performance of OTFTs is evaluated with field-effect mobility $(\mu)$ and threshold voltage $\left(V_{T}\right)$ extracted using the saturated drain current $I_{D}$ vs. $V_{G}$ relation [13]:

$$
I_{D}=\frac{W}{2 L} C_{i} \mu\left(V_{G}-V_{T}\right)^{2}
$$

where $\mathrm{W}, \mathrm{L}$ and $\mathrm{C}_{\mathrm{i}}$ are channel width, channel length and gate dielectric capacitance per unit area, respectively. From the transfer characteristics (shown in Fig. 6b) expressed as the square root of $\mathrm{I}_{\mathrm{D}}$ with $\mathrm{V}_{\mathrm{G}}$, mobilities and threshold voltages of these devices are obtained and listed in Table 1. The COP2 device shows high mobility that is about 6 times greater than that of the COP1 device. On the other hand, mobility dependence on electric field (E) is shown in Fig. 7. Mobility increases with $\mathrm{E}$ and at the same electric field $(|\mathrm{E}|>1 \mathrm{MV} / \mathrm{cm})$, the mobility of the COP2 device is $3 \sim 4$ times greater than that of the COP1 device, which originated from highly ordering of pentacene thin films deposited on the COP2 film. 
Table 1 Summary of solvents and their boiling points, $\mathrm{Ci}$ and film thicknesses of COP film,and mobilities and threshold voltages of OTFTs

\begin{tabular}{|c|c|c|c|c|c|c|}
\hline NO. & Solvent & $\begin{array}{l}\mathrm{BP} \\
\left({ }^{\circ} \mathrm{C}\right)\end{array}$ & $\begin{array}{c}\mathrm{C}_{\mathrm{i}} \\
\left(\mathrm{nF} / \mathrm{cm}^{2}\right)\end{array}$ & $\begin{array}{l}\text { Film thickness } \\
\qquad(\mathrm{nm})\end{array}$ & $\begin{array}{l}\text { mobility } \\
\left(\mathrm{cm}^{2} / \mathrm{Vs}\right)\end{array}$ & $\begin{array}{l}V_{T} \\
(V)\end{array}$ \\
\hline COP1 & cyclohexane & 81 & 4.55 & 450 & 0.32 & -23.8 \\
\hline COP2 & trimethylcyclohexane & 136.6 & 6.55 & 330 & 2.00 & -27.3 \\
\hline
\end{tabular}

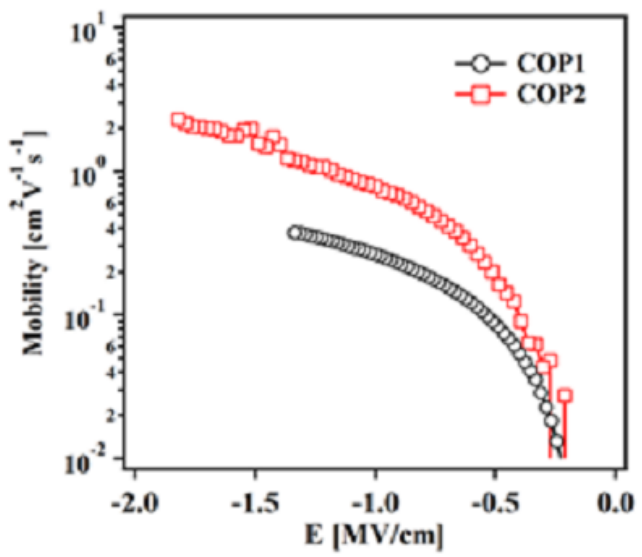

Fig .7 Mobilities dependence fo the COP1 device and the COP2 device on electric field(E) calculated from the derivatives of Id vs.Vg shown in Fig.6b

\section{Conclusions}

We have investigated the effects of the polymeric dielectric morphology on pentacene morphology and OTFT characteristics. The morphology and thickness of the polymer dielectric could be controlled by selecting a solvent. Higher the solvent's BP is, thinner and smother COP films could be obtained. Using the solvent of trimethylcyclohexane, the spin-coated COP films of ca. $330 \mathrm{~nm}$ with the P-V of $7.35 \mathrm{~nm}$ and RMS of $0.58 \mathrm{~nm}$ were obtained, and pentacene TFT showed high mobility of $2.0 \mathrm{~cm}^{2} \mathrm{~V}^{-1} \mathrm{~s}^{-1}$, which originated from highly ordering of pentacene thin films deposited on the smoother COP films.

\section{References}

1. S. R. Forrest: Nature 428, 911(2004).

2. R. Ye, T. Oyama, K. Ohta, M. Baba: Phys. Procedia, 14, 172 (2011).

3. S. Y. Yang, K Shin, C. E. Park: Adv. Funct. Mater. 15, 1806 (2005).

4. K.E. Strawhecker, S.K. Kumar, J.F. Douglas, A. Karim: Macromolecules 34, (2001) 4669.

5. D. F .S. Petri, J. Braz: Chem. Soc., 13, 695 (2002).

6. C. B. Walsh, E.I. Franses: Thin Solid Films, 429, 71 (2003).

7. Y. C. Lin, M. Müler, K. Binder: J. Chem. Phys., 121, 3816 (2004).

8. E. Ferrari, P. Fabbri, F. Pilati: Langmuir, 27, 1874 (2011).

9. D.W. Schubert, Polym. Bull., 38, 177 (1997).

10. D. B. Hall, P. Underhill, J. M. Torkelson, J. M. Polym, Eng. Sci. 38, 2039 (1998).

11. J. Gu, M. D. Bullwinkel, G.A. Campbell, Polym. Eng. Sci., 36, 1019 (1996).

12. M. Yamazaki: J. Mol. Cat. A Chem., 213, 81 (2004).

13. M. Sze: Physics of Semiconductor Devices (Wiley, New York, 1981). 